\title{
Global Warming Potential Implications and Methodological Challenges of Road Transport Emissions in Nigeria
}

\author{
S. C. Nwanya ${ }^{1} \&$ I. Offili ${ }^{2}$ \\ ${ }^{1}$ Department of Mechanical Engineering, University of Nigeria, Nsukka, Nigeria \\ ${ }^{2}$ Projects Development Institute (PRODA), Emene, Enugu, Nigeria \\ Correspondence: S. C. Nwanya, Department of Mechanical Engineering, University of Nigeria, Nsukka, Nigeria. \\ Tel: 234-805-725-0082. E-mail: stephen.nwanya@unn.edu.ng
}

\author{
Received: February 12, 2013 Accepted: March 28, 2013 Online Published: April 11, 2013 \\ doi:10.5539/eer.v3n1p169 URL: http://dx.doi.org/10.5539/eer.v3n1p169
}

\begin{abstract}
The purpose of this study is to examine the repercussions vehicular road transport emissions have on global warming potential (GWP), and the need to address the issue considering methodological challenges facing road transportation in Nigeria. Specific objectives of the study includes to determine the emission level in the country, to evaluate the GWP and to develop a emission mapping network on trunk A roads in Nigeria. Accurate information on these emissions is required to strengthen the mitigation and adaptation ability of the country to tackle climate change. The study relied on direct measurement technique supported by literature as well as questionnaires administered on the organised vehicle fleet operators and road traffic management agency as data gathering methods. Also, detailed analysis of questionnaires responses was carried out. Results show that road transport account for over $14 \%$ of greenhouse gases. Survey findings indicate that excessive smoke emission offence accounts for $1-2 \%$ of the annual road traffic offences in Nigeria. Using Statistical Package for Social Science (SPSS) software version 16, five fitted simple linear regression models were developed. With these fitted models it is possible to map the gas concentrations on the kilometre travelled. Examination of the National Vehicle Identification Scheme (NVIS) revealed a rise in the periodic plate number generation from yearly record of 788,169 in 2001 to 791,832 in 2009 . Human capacity requirements, based on yearly Drivers Licence (DL) processed, increased by 55\% between 2000 and 2010. Three mutual strategies namely renewed urban and rural road transport infrastructure availability, regular fleet maintenance and capacities building for improved behavioural change of road users were recommended to help control road transport emissions. These measures if inflexibly implemented will change the transport sector from being a major global warming risk factor to that of Eco-friendly sector.
\end{abstract}

Keywords: global warming potential, climate change, vehicle emissions, emission mapping, Nigeria

\section{Introduction}

In future, the rate of greenhouse gases from road transport will likely be growing faster than that from gas flaring in Nigeria. A proxy indicator of the generic cause of this emissions rate is the growing demand for personal automobile (motorcycles, tricycles, cars, trucks and tanks) ownership without a change in travel behaviours. The foregoing argument implies that vehicular emissions are inevitable corollary of the desire to meet societal mobility needs. Consequently, a large amount of greenhouse gas emissions are expected because the vehicles are operated primarily on fossil fuels. Vehicle fleets emissions are primary source of ozone precursors (Jones \& Stokes, 2007). Potency of these emissions depends on quantity released and specific heat trapping property of each range (Perez et al., 2013).

The increasing intensity and heat trapping abilities of the emissions have direct consequence on warming of the earth's atmosphere referred to as global warming. Global warming potential (GWP), therefore, is a ratio of the amount of radiation a unit emission of the gas absorbs over a time frame, as compared with how much radiation a unit emission of $\mathrm{CO}_{2}$ absorbs in the atmosphere over the same time period (Anonymous, 2012). While there is no clear consensus on global warming among scientist (Lindzen, 1992), there is a reality of its impact on ecosystem. There is also, a growing recognition that we cannot stop global warming (Igwenagu, 2011), however, we can manage their spiral effects including high global warming potential arising particularly from vehicle activities. 
The purpose of this study is to examine implications of rising global warming potentials of greenhouse gas from road transport. Six physical elements of the transport sector can influence the GHG emissions: vehicle fuel efficiency, green house gas intensity of fuel used, amount of transport activity, mode of transport chosen, amount of capacity occupancy used and changes in vehicle ownership (Robinson, 1997; Briol \& Guerer, 1993; Al-Naima $\&$ Hamd, 2012). For developing countries, where there is dominance of road transportation, these elements are expected to influence emission of more greenhouse gases than urbanization challenges. Under this situation, road transportation has great prospects for innovative investment opportunities in one respect. In another respect, there is air pollution as a liability. Finding sustainable solutions to the liability motivates this study.

In addition, transport sector in Nigeria is challenged by other factors including dilapidated road network, old and poorly maintained vehicle fleet and inept human capacity base. The follow-on effects of these factors can accelerate global warming. When the road is bad, it affects everybody because materials and human beings have to be moved from one location to another (Nneji, 2012). The poor state of our roads is worsened by over reliance on road transportation for mobility of goods and services resulting in avoidable accidents and traffic gridlock as shown in Figure 1a and 1b. The traffic gridlock can be compared to a queuing system. It increases vehicles fuel consumption and cost for running a normal short distance trip. For road unworthy vehicles, gridlock produces a large volume of harmful GHG emissions which contribute to global warming and can cause more short-term and localised problems, such as smog and respiratory problems (Musbau, 2012). Also, traffic congestions pose serious security risks in addition to loss of productive time. However, this study focuses on the global warming implications because of its life-threatening consequences on environment.

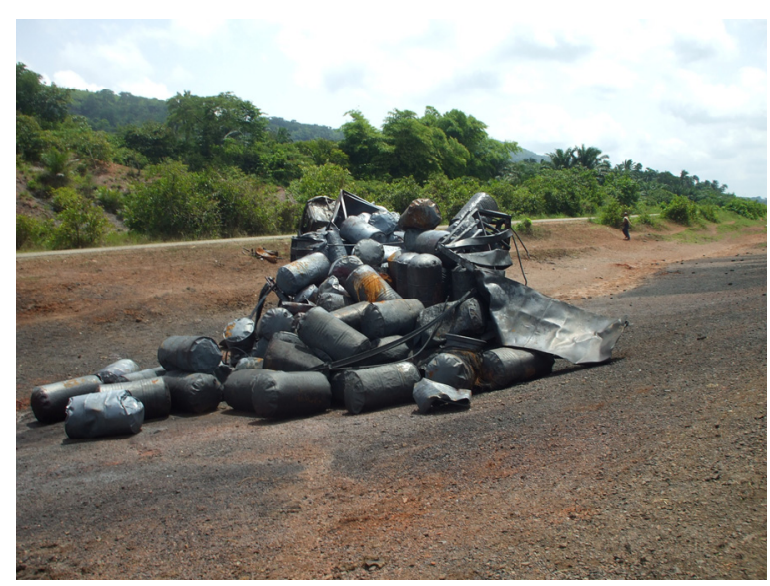

(a)

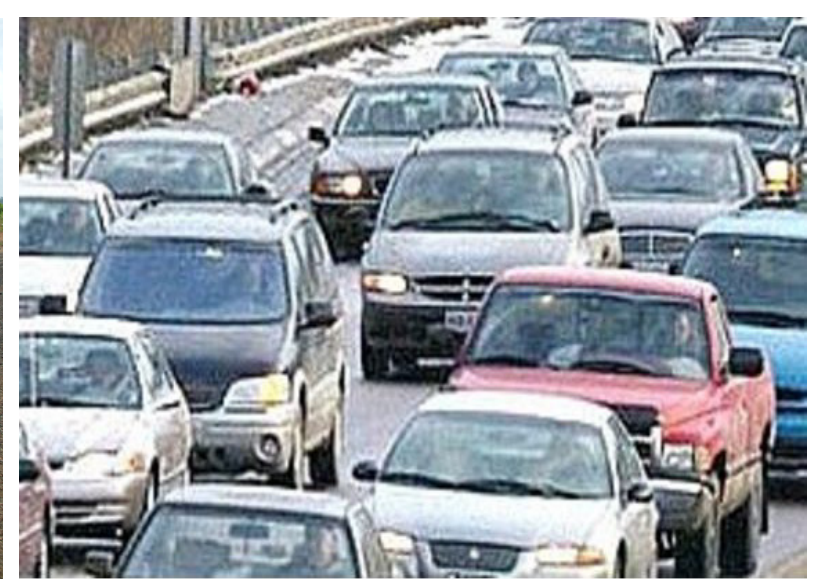

(b)

Figure 1. (a) accidental hazards due to dilapidated road; (b) traffic gridlock

The main pollutants from vehicle emissions are $\mathrm{NO}_{\mathrm{x}}, \mathrm{CO}_{2}, \mathrm{CO}, \mathrm{SO}_{2}$, and $\mathrm{CH}_{4}$. Pollution of ambient air with these elements all together constitutes environmental and human health hazards to the society. With increasing demand for personal automobile ownership due to impaired public transport modes, the insidious impacts of vehicle emissions are expected to continue in the future. In this context, upward trend in consumption of transport fuels and more emissions are expected (Birol \& Guerer, 1993). Therefore, evaluation of the global warming potential of road transport emission is pertinent in order to evolve adaptation and mitigation strategies, especially for the associated climate change implications.

Adaptation and mitigation to climate change should be taken together because they have an inseparable link. Their linkage can be understood by the fact that adaptation practice alone cannot save a patient from continuous over dosage of a drug. There should be strategies to mitigate over dosage. In a similar sense, the fragile ecosystem is under continuous overdose of impacts of climate change and require both mitigation and adaptation strategies for continued existence. According Kane and Shogren (2000), both strategies jointly determine our risks and the costs of decreasing those risks. They each influence the timing and level required of the other (Munasinghe \& Swart, 2005; Wilbanks et al., 2003) and their responses depend on social and technological constraints. 
Unless inventory of vehicle emissions are evaluated and their links with social and technological constraints explored, there can be no effective control of their production. Recent studies have treated vehicle emissions both in ethnographic spread and content analysis. In the context of ethnographic occurrence, (Abam \& Unachukwu, 2009; Utang \& Peterside, 2011; Ndoke et al., 2012; Moen, 2012; Musbau, 2012) focused on Calabar, Port Harcourt, North Western Nigeria, Abuja and Lagos cities, respectively. These studies employed sampling technique of USEPA standard using portal analyser to estimate road transport pollutant indicators at spots or sampling points that designate high congestion and dense population. In terms of report content, Ojolo et al. (2007) presented a generalised analysis of the impact of vehicle emissions on human health in Nigeria and Utang Peterside (2011) identified spatio-temporal variations in vehicle emissions between traffic peak and off peak periods in Port Harcourt city. These studies have their strength and weaknesses as well as criteria for selection of sampling locations that are inimical to emission from mobile sources.

It is common knowledge that vehicle emission concentrations vary with engine operating mode, which include idling, decelerating, cruising and accelerating. The present literature on the subject so far has treated and evaluated emissions from automotive at traffic jam and sampling points alone. There seems no documentation exists that covers major road networks across all geographic areas. In order to close this gap, the emission mapping of traffic pollutants along the roads between Abuja and States capital is important and addressed in this study.

The objectives of this study include determining the emission level in the country, evaluating the GWP and developing an emission mapping network on trunk "A" roads in Nigeria. In carrying the study, relevant data were obtained through questionnaires and interviews methods. Contacts were made to competent personnel of the Federal Road Safety Commission (FRSC) (a typical traffic management system) and the organised vehicle fleet operators while the obtained data were used to compute GWPs indices. Unlike the treatment in the present literature on the subject GHGs emission this study developed a mapping methodology. This methodology is a consistent approach for calculating the GHGs emission along the major trunk A roads connecting Abuja city with State capitals. The mapping is with a view to identifying road networks that lead to higher emissions and capacity expansion options for the sector. The approach is robust and exploits travel behaviour (cruise, accelerating and decelerating) applicable for intercity connections.

\subsection{Background Information and Justification for the Work}

Globally, transportation service is conducted mainly by water ways, road, railways and airways. These modes collectively provide safer and faster ways for movement of goods and services. But, transportation in Nigeria is a harrowing experience due to over reliance on road transport vehicles. Road transport is the most popular; accounting for $75 \%$ of mobility needs and has widest spread of transport network in Nigeria. The country has $195,000 \mathrm{~km}$ national road network, with federal roads accounting for 17\% (Nigerian Engineer, 2012), current vehicle population exceeding seven million (Agbo, 2011) and average density of 11 vehicles per kilometre (Musbau, 2012).

The population of Nigeria is 140 million people from 250 ethnic nationalities. The ethnic nationalities have been grouped into 36 States as shown in Figure 2 with Abuja as federal capital for administrative convenience and political governance. The roads linking the States with Abuja have high traffic density, which informed their choice for this study. Abuja is Nigeria's fastest growing city with a per annum growth rate of $5 \%$ and low industrial development (Moen, 2012). The overall rate of urbanization in Nigeria is 5.6\%. Therefore, high level socio-economic and political interactions between the States and Abuja necessitate intensive transportation services. However, lack of railways and waterways as well as unreliable airways systems connecting the States and federal capital have resulted in heavy vehicle activity with the associated GHG emissions.

The actual and potential effects of concentrating on single mode of transport, according to Robinson (1997), are large-global climate change, ozone depletion, smog, congestion, noise and urban sprawl. Estimation of the level of concentration of gas emissions and associated impacts like global warming under heavy vehicular activity is the main thrust of this study.

The vehicle activity is defined here as the distance covered by vehicles between the States and federal capital routes. The associated emissions have global warming potential implications. Global warming potential implies increase irradiative capacity or ability to trap ambient heat. These implications in addition to deplorable state of the roads make road travel unpleasant and stressful or sometimes result in human health problems. The argument against this worrisome experience has led to short term recommendations for strict control measures such as restriction on importation of old vehicles and elimination of lead concentration in gasoline. But, these measures 
hardly offered reasonable relief and for this reason complementary solutions are required. Long term measure will include emission mapping that will ensure optimization of the potency level of the GHGs.

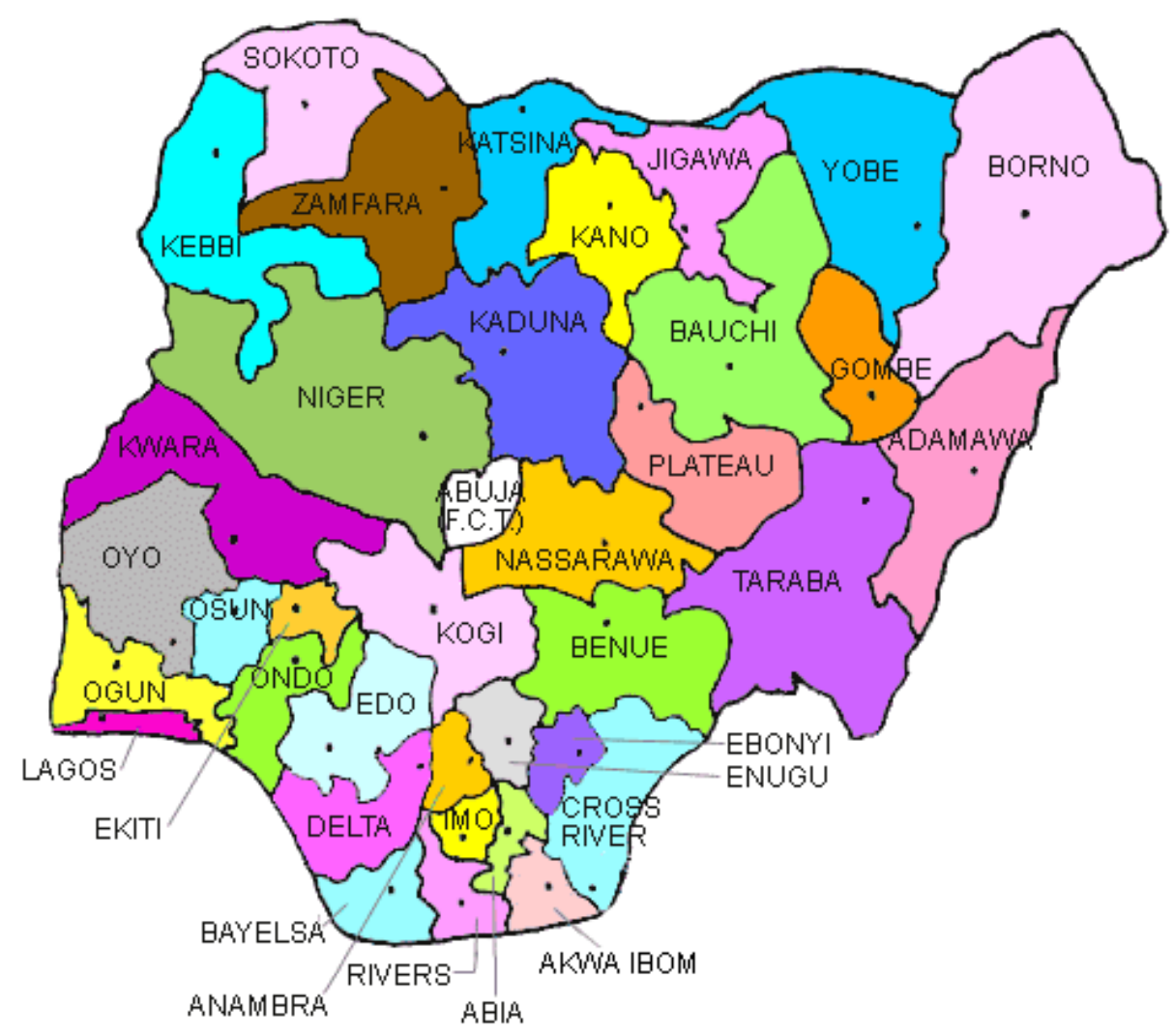

Figure 2. Map of Nigeria showing the 36 States and Abuja capital

\section{Challenges of the Road Transportation System in Nigeria}

A comparison of modes of powering road transport vehicles clearly indicates that whereas electric mode ranks second to internal combustion engines in terms of cost-benefits, the former remains the best in terms of air pollution effects. Electric vehicle offers an improved overall thermodynamic efficiency (Muneer et al., 2011). However, electric vehicles are uncommon in Nigeria and replacement of internal combustion engine with electric type involves huge capital investment in infrastructure and capacity building. Also, the growth potential of road transport has been associated with corresponding increased energy intensity. Energy intensity is defined here as the energy use per vehicle kilometre in the case of cars, energy use per tonne kilometre for goods vehicle, rail, marine and air freight, and energy per passenger kilometre for bus, air and rail transport ( Michaelis, 1997).

Efficient and safe road transportation is among the missing critical success factors in the drive towards a productive economy in Nigeria. This problem undermines sustainable development, particularly economic transformation that stems from mobility of human, goods and services. Ineffective transport system in Nigeria has been attributed to low quality of human capacity in the sector, increasing number of old and poorly maintained vehicle fleet, over stretching of road and its substitution for rail and water ways. How can these issues be handled with a view to innovatively tap the job creative opportunities of road transport sector?

\subsection{Capacity Building and Training for Promotion of Reliable Road Transport System}

The road transportation management in Nigeria is challenged by unskilled human capacity base. The effect of this problem on the society includes high accident rate and $70 \%$ of it is attributed to ineptitude. Without qualified and tested human capacity base, there can be no effective road transportation system. Capacity building is prescribed here as a part of the way forward.

Capacity building in the context of road transportation sector involves a process of assisting people to develop their technical and decision making skills for getting it right when faced with road challenges. The road transport 
sector like most other sectors should benefit from the abundant human resources in the country. The jobs available in the sector are such that the seeker creates them and can just do that only if the requisite skills have been embedded. In view of this reason, the human capacity aspect of the road transport administration can, as a general rule of management, only increase productivity if the capacity is enhanced. Are there possibilities for this purpose in contemporary Nigeria?

\subsection{Fleet Maintenance, Elimination of Aging and Air Polluting Vehicles}

The social and economic consequences of heavy road vehicular traffic has remained an under- surface problem in Nigeria. Nigeria is highly dependent on second-hand used imported vehicles that place great burden on the environment in terms of energy consumption and air pollution. Imported brand new vehicles that have high fuel efficiency are expensive and mostly affordable by government agencies and few corporate organizations. The above stated trend of vehicle importation has remained difficult to change since the few assemble plants closed shops in Nigeria. Introduction of road user charges such as excessive emission charges, fuel taxes and vehicle import taxes rated in proportion to age of manufacture will address the intractable emission level. The argument for these charges is to let the polluter pay cost for damages caused. For effective implementation of emission charge, it should be pressed on vehicles that fail a yearly tailpipe test.

Apart from the age of vehicles, improper fuel combustion techniques precipitated by untrained operators/ drivers also accounts for the rising social and economic costs of fleet management. Muneer et al. (2011), has reported that $23 \%$ of energy losses in vehicles are due to frequent standby and breaking by drivers. This leads to more $\mathrm{CO}_{2}$ emissions.

Another alternative way forward includes adoption of railway system as widely accepted means of mass freight and passenger transport, use of electric vehicles and renewable energy-based vehicles that will facilitate green technology transformation in Nigeria.

\subsection{Urban and Rural Transport Infrastructure Availability}

Road construction and maintenance in both urban cities and rural communities are twin indicators of good governance. But, they are lacking in Nigeria, while dilapidated tarred and eroded laterite-paved roads embellish the traffic ways.

The problem can be solved by involving private partnership with government in road construction and maintenance. Urban and rural road construction will reduce traffic congestion in the light of increasing vehicle ownership in the economy. Therefore, a strategy will be adopted through which the private sector recovers the investment in road construction and maintenance such as through road toll concession.

Three mutual strategies that need to be reinforced to ensure control of road transport emission and at the same time reduce the challenges are: renewed urban and rural transport infrastructure availability, regular fleet maintenance, consistent check on aging and air polluting vehicles, and capacity building for improved behavioural change of road users. These measures if inflexibly implemented will change the transport sector from being a major global warming risk factor to that of Eco-friendly sector.

\section{Materials and Methods}

Quantifying the current emissions from road transport is a crucial first step to determining the environmental impact of the sector. The approach used followed estimation of emission quantities and questionnaire administration. As for the basic emissions quantification, we have followed aforementioned instantaneous measurements conducted in Nigeria, but have modified these wherever this seemed appropriate so as to avoid built-in biases. The instantaneous measurements monitored directly air quality parameters through a Testo 350XL Emission Analyzer. The monitoring was conducted for a minimum of 72 hours at road intersections having records of perennial traffic congestions. Emissions concentration data were collected at hourly intervals for peak and off-peak periods. The concentrations are measured in parts per million. The monitoring process followed the pattern of exhaust testing.

In this regard, the average of the common emission values is calculated with at least one more figure than that of the data as follows:

$$
\bar{y}=\frac{1}{n} \sum y_{i}
$$

Where $\mathrm{n}=$ total number of sample observations, $\mathrm{i}=1$ to 3 parameters,

To calculate the greenhouse gases emissions from transport sector, the following are necessary: 
- Obtain emission concentration factor of each of GHG pollutants and the transport activity data for the national territory

- The activity data is obtained from measurements, while emission factors are instantaneous values in concentration form, parts per million (ppm)

- The instantaneous values are converted from ppm to an equivalent mass values in kilogram

- Using the activity data and emission factors, then calculate emission concentrations generated that are specific to each GHG

- The GHG emissions are reported in terms of $\mathrm{CO}_{2}$ equivalent. The $\mathrm{CO}_{2}$ equivalent is determined by multiplying the amount of emissions of a particular gas by its specific global warming potential index. Table 1 shows specific global warming potential indices of some of the gases.

- Also, an assumption is made that the concentration of pollutants in atmosphere is influenced by weather conditions which are different in space and time (Utang et al., 2011).

To reduce all values to single unit, the concept million metric tons of carbon equivalent (mmtce) is used (GEF, 2010).

Table 1. Global warming potential indices of some of greenhouse gases

\begin{tabular}{lllll}
\hline \multirow{2}{*}{ Gas } & Lifetime & \multicolumn{3}{l}{ Global warming potential time horizon } \\
\cline { 2 - 5 } & Years & 20 years & 100 years & 500 years \\
\hline Methane $\mathrm{CH}_{4}$ & 12 & 72 & 25 & 7.6 \\
Nitrous Oxide $\mathrm{N}_{2} \mathrm{O}$ & 114 & 289 & 298 & 153 \\
Hydrofluorocarbon HFC-23 & 270 & 1200 & 14,800 & 12,200 \\
Hydrofluorocarbon HFC-134a & 14 & 3800 & 1430 & 435 \\
Sulphur Hexafluoride & 3200 & 16300 & 22,800 & 32,600 \\
\hline
\end{tabular}

Source: GEF, 2010.

\section{Results and Discussion}

For the purpose of this study, 36 heavily trafficked routes that link the 36 States of Nigeria with Abuja were used to represent the traffic activity. A questionnaire survey considered predominant automotive vehicle types in Nigeria irrespective of model and fuel types. The investigation showed that cars, buses and jeeps are common on our roads. Also, results of the questionnaire survey show that some of the respondents spend 30 to 60 minutes of their travel time at traffic congestion. Human capacity requirements for transport sector, based on yearly Drivers Licence (DL) processed, increased by 55\% between 2000 and 2010 . This implies a growth rate of 5.5\% if spread evenly within the range of period being considered. This growth rate is significant in view of rising number of personal automobile ownership. It can be inferred that with the $5.5 \%$ and more vehicles operated on fossil fuel, there will be a corresponding increase in amount of emissions resulting to high GWPs. The survey analysis also, showed that overall annual smoke emission offences accounts for $1 \%$ to $2 \%$ of road traffic offence.

For the objective measurement of exhaust gas emissions from these vehicles, the study adopted direct measurements monitored by Abam and Unachukwu (2009), Moen (2012), Utang and Peterside (2011). The decision to adopt these values was taken because the authors followed international standard practices similar to the strategy proposed for this study. Also, the following: $\mathrm{NO}_{\mathrm{x}}, \mathrm{CO}_{2}, \mathrm{CO}, \mathrm{SO}_{2}$, and $\mathrm{CH}_{4}$ were monitored at different geographical zones with peak and off-peak periods within same range of ambient conditions which fairly represent national conditions. Table 2 shows some of the different readings.

The concentration levels shown in Table 2 collaborates with the survey questionnaire findings that excessive smoke emission offence accounts for $1-2 \%$ of the annual road traffic offences in Nigeria. Also, road transport account for over $14 \%$ of national greenhouse gas emissions.

The aforementioned values are constrained to increase when examined along side the rising rate of vehicle ownership, both government and private in the country. Table 3 shows the ownership structure through periodic National Vehicle Identification Scheme (NVIS) registration. 
Table 2. Some of the hourly ambient gas concentrations of vehicular emissions in Nigeria

\begin{tabular}{lllllll}
\hline City & $\mathrm{CO}(\mathrm{ppm})$ & No. observations & $\mathrm{SO}_{2}(\mathrm{ppm})$ & No. observations & $\mathrm{NO}_{2}(\mathrm{ppm})$ & No. observations \\
\hline Abuja & 24 & 20 morning & 0.6 & 22 morning & $\mathrm{N} / \mathrm{A}$ & N/A \\
Abuja & 16 & 23 afternoon & 0.3 & 24 afternoon & N/A & N/A \\
Calabar Day 1 & 6.177 & 9 morning & 0.062 & 9 morning & 0.05 & 9 morning \\
Calabar Day 2 & 5.7 & 9 morning & 0.07 & 9 morning & 0.05 & 9 morning \\
Calabar Day 3 & 5.8 & 9 morning & 0.07 & 9 morning & 0.05 & 9 morning \\
Port Harcourt & 5.5 & 4 peak morning & 0.004 & 4 peak & 0.43 & 4 peak \\
Port Harcourt & 16.07 & 4 peak evening & N/A & N/A & 0.95 & 4 peak \\
\hline
\end{tabular}

Source: Abam and Unachukwu (2009), Moen (2012), Utang and Peterside (2011).

$\mathrm{N} / \mathrm{A}=$ not available.

Table 3. National vehicle identification scheme (NVIS) showing vehicle ownership structure in Nigeria

\begin{tabular}{llllllllll}
\hline Organization & Year-2001 & 2002 & 2003 & 2004 & 2005 & 2006 & 2007 & 2008 & 2009 \\
\hline Military/Param.(MV) & 226 & 0 & 10,365 & 839 & 2,366 & 429 & 2,360 & 2,449 & 2,205 \\
Military/ Param.(MC) & 0 & 0 & 344 & 30 & 12 & 319 & 1,060 & 202 & 354 \\
Diplomatic (MV) & 3,427 & 0 & 682 & 413 & 1,084 & 437 & 269 & 166 & 90 \\
Diplomatic (MC) & 5 & 0 & 0 & 0 & 0 & 0 & 1 & 1 & 5 \\
Federal Govt (MV) & 13,532 & 26,096 & 12,721 & 2,576 & 2,515 & 3,203 & 4,311 & 3,556 & 3,354 \\
Federal Govt. (MC) & 176 & 266 & 1,648 & 199 & 744 & 4,440 & 770 & 1,692 & 487 \\
State Govt. (MV) & 317 & 863 & 48,975 & 3,911 & 5,068 & 5,734 & 7,399 & 8,007 & 8,456 \\
State Govt. (MC) & 0 & 0 & 7,985 & 623 & 1,300 & 1,545 & 1,502 & 1,202 & 1,384 \\
Local Govt. (MV) & 0 & 124 & 14,136 & 811 & 744 & 788 & 480 & 2,508 & 1,299 \\
Local Govt. (MC) & 0 & 0 & 3,251 & 142 & 285 & 113 & 166 & 653 & 204 \\
Private (MV) & 400,014 & 383,750 & 238,913 & 206,102 & 167,032 & 178,061 & 204,887 & 231,756 & 252,126 \\
Private (MC) & 163,822 & 187,489 & 248,216 & 203,908 & 217,862 & 308,228 & 284,206 & 351,247 & 343,888 \\
Commercial (MV) & 124,498 & 91,631 & 59,202 & 49,558 & 57,526 & 53,322 & 51,901 & 71,064 & 90,937 \\
Commercial (MC) & 82,152 & 109,608 & 94,345 & 92,002 & 72,541 & 97,133 & 66,792 & 87,499 & 87,043 \\
Total & 788,169 & 799,827 & 740,783 & 561,114 & 529,079 & 653,752 & 626,104 & 762,002 & 791,832 \\
\hline
\end{tabular}

Source: Federal Road Safety Corps (FRSC), Wuse Zone 2, Abuja, Nigeria.

The prior stated gaseous concentrations in Table 2 are emitted as exhaust gases from the automotive engine and into the atmosphere through the exhaust ports, exhaust manifold, exhaust pipe, muffler, and tail pipe. They are still average point data (as calculated using Equation 1) and monitored within a kilometre range. To calculate the instantaneous gases emitted in mass units, a measured exhaust flue gas volume flow rate $\left(\mathrm{V}_{\text {exh. }}\right)$ of $1200 \mathrm{CFM}$ $\left(0.564 \mathrm{~m}^{3} / \mathrm{s}\right)$ is used. To obtain the mass units for each of $\mathrm{NO}_{2}, \mathrm{CO}$ and $\mathrm{SO}_{2}$, these steps were followed:

$$
\begin{gathered}
V_{\text {exh. }}=3600 \times 0.564\left[\mathrm{~m}^{3} / \mathrm{h}\right] \\
M_{\text {poll.i }}=\text { Con }_{\text {poll. } . i} \times 10^{\wedge}-6 \times \rho_{\text {pool. } i} \times V_{\text {exh. }}[\mathrm{kg} / \mathrm{h}]
\end{gathered}
$$

Where:

$\mathrm{M}_{\text {poll.i }}=$ mass emission of pollutant, $\mathrm{I}=1$ to $\mathrm{n}, \mathrm{Con}_{\text {poll }}=$ concentration pollutant in parts per million, $\mathrm{P}=$ density of pollutant, $\mathrm{g} / \mathrm{dm}^{3}, \mathrm{~V}_{\text {exh. }}=$ exhaust volume flow rate $\mathrm{m}^{3} / \mathrm{s}, \mathrm{m}=$ metre, $\mathrm{h}=$ hour and 3600 multiplies $0.564 \mathrm{~m}^{3} / \mathrm{s}$ to get the cubic metre per hour.

Each quantity of gas emitted can be appraised with traffic activity or vehicle kilometre travelled (VKT) and vehicle type as well as vehicle population. The impacts of the three independent variables on emission concentration and GWP are investigated among the 36 States in this study as shown in Table 4. 
Table 4. Effect of traffic activity and vehicle population on gaseous concentration

\begin{tabular}{|c|c|c|c|c|c|c|c|c|}
\hline City & VKT & VP & $\mathrm{a}$ & b & $\mathrm{c}$ & d & $\mathrm{e}$ & $\mathrm{f}$ \\
\hline Abeokuta & 740 & 116895 & 16616.7 & 1.14256 & 0.000772 & $1.94 \mathrm{E}+09$ & 133559.6 & 90.2219 \\
\hline Akure & 700 & 86273 & 15718.5 & 1.0808 & 0.00073 & $1.36 \mathrm{E}+09$ & 93243.86 & 62.98792 \\
\hline Asaba & 404 & 137615 & 9071.82 & 0.623776 & 0.000421 & $1.25 \mathrm{E}+09$ & 85840.93 & 57.98711 \\
\hline Awka & 440 & 134227 & 9880.2 & 0.67936 & 0.000459 & $1.33 \mathrm{E}+09$ & 91188.45 & 61.59945 \\
\hline Bauchi & 445 & 63995 & 9992.475 & 0.68708 & 0.000464 & $6.39 \mathrm{E}+08$ & 43969.68 & 29.70232 \\
\hline Benin city & 450 & 99540 & 10104.75 & 0.6948 & 0.000469 & $1.01 \mathrm{E}+09$ & 69160.39 & 46.7191 \\
\hline Birin Kebbi & 573 & 31681 & 12866.72 & 0.884712 & 0.000598 & $4.08 \mathrm{E}+08$ & 28028.56 & 18.9338 \\
\hline Calabar & 857 & 108551 & 19243.94 & 1.323208 & 0.000894 & $2.09 \mathrm{E}+09$ & 143635.6 & 97.02842 \\
\hline Damaturu & 757 & 52182 & 16998.44 & 1.168808 & 0.00079 & $8.87 \mathrm{E}+08$ & 60990.74 & 41.20035 \\
\hline Dutse & 512 & 35109 & 11496.96 & 0.790528 & 0.000534 & $4.04 \mathrm{E}+08$ & 27754.65 & 18.74877 \\
\hline Bayelsa & 930 & 148152 & 20883.15 & 1.43592 & 0.00097 & $3.09 \mathrm{E}+09$ & 212734.4 & 143.706 \\
\hline Ebonyi & 695 & 148986 & 15606.23 & 1.07308 & 0.000 & $2.33 \mathrm{E}+09$ & 159873.9 & 107.9977 \\
\hline Ado-Ekiti & 600 & 85062 & 13473 & 0.9264 & 0.000626 & $1.15 \mathrm{E}+09$ & 78801.44 & 53.2318 \\
\hline Enugu & 595 & 105370 & 13360.73 & 0.91868 & 0.000 & $1.41 \mathrm{E}+09$ & 96801.31 & 65.39104 \\
\hline Ibadan & 659 & 182201 & 14797.85 & 1.017496 & 0.000687 & $2.7 \mathrm{E}+09$ & 185388.8 & 125.2335 \\
\hline Ikeja & 879 & 463349 & 19737.95 & 1.357176 & 0.000917 & $9.15 \mathrm{E}+09$ & 628846.1 & 424.797 \\
\hline Ilorin & 500 & 56135 & 11227.5 & 0.772 & 0.000522 & $6.3 \mathrm{E}+08$ & 43336.22 & 29.2744 \\
\hline Jalingo & 591 & 31688 & 13270.91 & 0.912504 & 0.000616 & $4.21 \mathrm{E}+08$ & 28915.43 & 19.5329 \\
\hline Gombe & 501 & 53829 & 11249.96 & 0.773544 & 0.000523 & $6.06 \mathrm{E}+08$ & 41639.1 & 28.12797 \\
\hline Jos & 313 & 92762 & 7028.415 & 0.483272 & 0.000326 & $6.52 \mathrm{E}+08$ & 44829.28 & 30.28299 \\
\hline Kaduna & 180 & 121926 & 4041.9 & 0.27792 & 0.000188 & $4.93 \mathrm{E}+08$ & 33885.67 & 22.89039 \\
\hline kano & 442 & 199154 & 9925.11 & 0.682448 & 0.000461 & $1.98 \mathrm{E}+09$ & 135912.2 & 91.81119 \\
\hline Katsina & 533 & 44307 & 11968.52 & 0.822952 & 0.000556 & $5.3 \mathrm{E}+08$ & 36462.53 & 24.6311 \\
\hline Keffi & 80 & 151602 & 1796.4 & 0.12352 & $8.34 \mathrm{E}-05$ & $2.72 \mathrm{E}+08$ & 18725.88 & 12.64967 \\
\hline Gauzu & 660 & 87627 & 14820.3 & 1.01904 & 0.000688 & $1.3 \mathrm{E}+09$ & 89295.42 & 60.32067 \\
\hline Lokoja & 138 & 76142 & 3098.79 & 0.213072 & 0.000144 & $2.36 \mathrm{E}+08$ & 16223.73 & 10.95942 \\
\hline Madugiri & 908 & 88739 & 20389.14 & 1.401952 & 0.000947 & $1.81 \mathrm{E}+09$ & 124407.8 & 84.03974 \\
\hline Makurdi & 323 & 44591 & 7252.965 & 0.498712 & 0.000337 & $3.23 \mathrm{E}+08$ & 22238.07 & 15.02222 \\
\hline Minna & 117 & 77640 & 2627.235 & 0.180648 & 0.000122 & $2.04 \mathrm{E}+08$ & 14025.51 & 9.474487 \\
\hline Oshogbo & 428 & 96893 & 9610.74 & 0.660832 & 0.000446 & $9.31 \mathrm{E}+08$ & 64029.99 & 43.25342 \\
\hline Owerri & 733 & 127442 & 16459.52 & 1.131752 & 0.000765 & $2.1 \mathrm{E}+09$ & 144232.7 & 97.43183 \\
\hline P.Harcourt & 830 & 152396 & 18637.65 & 1.28152 & 0.000866 & $2.84 \mathrm{E}+09$ & 195298.5 & 131.9277 \\
\hline Sokoto & 703 & 91103 & 15785.87 & 1.085432 & 0.000733 & $1.44 \mathrm{E}+09$ & 98886.11 & 66.79936 \\
\hline Umuahia & 700 & 115638 & 15718.5 & 1.0808 & 0.00073 & $1.82 \mathrm{E}+09$ & 124981.6 & 84.4273 \\
\hline Uyo & 828 & 77824 & 18592.74 & 1.278432 & 0.000864 & $1.45 \mathrm{E}+09$ & 99492.69 & 67.20912 \\
\hline Yola & 855 & 55281 & 19199.03 & 1.32012 & 0.000892 & $1.06 \mathrm{E}+09$ & 72977.55 & 49.29766 \\
\hline
\end{tabular}

Source: authors.

Where: VKT $=$ vehicle kilometre travelled, $\mathrm{VP}=$ vehicle population, $\mathrm{a}=\mathrm{VKT}^{*}$ instantaneous ppm of $\mathrm{CO}, \mathrm{b}=$ $\mathrm{VKT} *$ instantaneous ppm of $\mathrm{SO}_{2}, \mathrm{C}=\mathrm{VKT} *$ instantaneous ppm of $\mathrm{NO}_{2}, \mathrm{~d}=\mathrm{VP} *$ instant. Ppm of $\mathrm{CO}, \mathrm{e}=\mathrm{VP}$ $*$ ppm of $\mathrm{SO}_{2}$, and $\mathrm{f}=\mathrm{VP} *$ ppm of $\mathrm{NO}_{2}$.

Using Statistical Package for Social Science (SPSS) software version 16, a five fitted simple linear regression models were developed. With these fitted models it is possible to map the gas concentrations on the kilometre travelled. Also, the fitted models show that gas concentrations are functions of population of automotive vehicles. Equations 4 and 5 demonstrate relationship between VKT and concentration, while equations 6,7 and 8 are for VP and concentration. 


$$
\begin{gathered}
C \hat{O}=22.455 V K \hat{T} ; r^{2}=1 \\
S \hat{O}_{2}=0.001 V K \hat{T} ; r^{2}=.68 \\
C \hat{O}=-5.258 \times 10^{\wedge} 8+1.7854 \times 10^{\wedge} 4 V \hat{P} ; r^{2}=.75 \\
S \hat{O}_{2}=-3.8328 \times 10^{\wedge} 4+1.26 V \hat{P} ; r^{2}=.796 \\
N \hat{O}_{2}=25.988+0.001 V \hat{P} ; r^{2}=0.829
\end{gathered}
$$

The developed models are useful for forecasting the gas concentrations in once the VKT and VP are known. With known concentration, emission factors can be estimated. Using the emission factor and activity data the GWP specific to each GHG is computed.

The GWP of each GHG is defined in relation to a given weight of $\mathrm{CO}_{2}$ and for a time period. Currently, GWP of gases are expressed in $\mathrm{CO}_{2}$ equivalents and it makes comparison of the potential effects of other gases possible (GEF, 2010). In this work, tons $\mathrm{CO}_{2} \mathrm{eq} / \mathrm{km}$ for three commonly available automobiles: cars, buses and jeeps in Nigeria were calculated based on their sample population. The result is shown in Figure 3. From Figure 3, it can be proved that increasing vehicular emissions have GWP and climate change implications on human health and the environment. Meanwhile in this study, reduced severity of impacts can be realized through improved changes in vehicle characteristics (efficiency), road characteristics (increase occupancy per peak hours) and travel preference mode.

\section{Conclusion}

In this study, a global warming potential implication of vehicle emissions and methodological challenges faced in a road dominated mode of transport has been examined. The greenhouse emissions have pollution effects and are the main cause of global warming and climate change. In carrying the study, relevant data were obtained through questionnaires and interviews methods.

Results show that road transport account for over $14 \%$ of greenhouse gases. The questionnaire analysis indicates that excessive smoke emission offence accounts for 1-2\% of the annual road traffic offences in Nigeria. Under the National Vehicle Identification Scheme (NVIS) the periodic plate number generation rose from yearly record of 788,169 in 2001 to 791,832 in 2009 . More so, the human capacity requirements, based on yearly Drivers Licence (DL) processed, increased by 55\% from 2000 to 2010. Using Statistical Package for Social Science (SPSS) computer software, a five fitted simple linear regression models were developed. With these fitted models it is possible to map the gas concentrations on the kilometre travelled. Road transport emissions have great climate change implications on human health and the environment. In Nigeria, challenges to efficient transportation have been attributed to low quality of human capacity in the sector, increasing number of old and poorly maintained vehicle fleet, over stretching of road and its substitution for rail and water ways. 


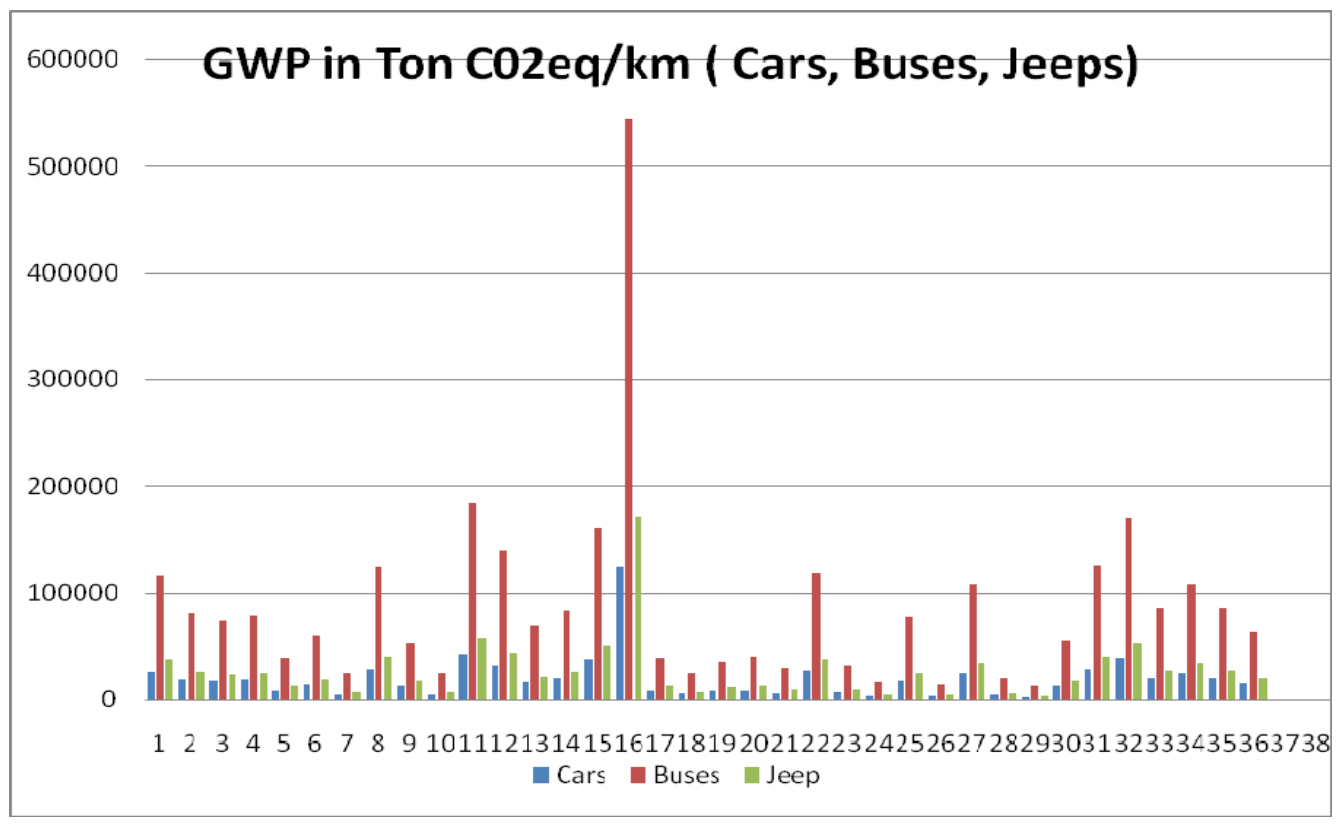

Figure 3. GWP in Ton $\mathrm{CO}_{2} \mathrm{eq} / \mathrm{km}$ for cars, buses and jeeps

Three mutual strategies are needed to control road transport emission and at the same time reduce the challenges are: renewed urban and rural transport infrastructure availability, regular fleet maintenance and capacity building for improved behavioural change of road users. Also, this study recommends a yearly tailpipe emission testing on all vehicles which qualifies them to ply on public roads. These measures if inflexibly implemented will change the transport sector from being a major global warming risk factor to that of Eco-friendly sector.

Information obtained from this study will help policy makers to formulate road pricing systems and plan for green technological transformation.

\section{References}

Abam, F. I., \& Unachukwu, G. O. (2009), Vehicular emissions and air quality standards in Nigeria. European Journal of scientific research, 34(4), 550-560.

Agbo, C. O. A. (2011). Recycle materials potential of imported used vehicles in Nigeria. Nigerian Journal of Technology, 30(3), 118-129.

Al-Naima, F. M., \& Hamd, H. A. (2012). Vehicle traffic congestion estimation based on radio frequency identification and wireless sensor networks. International J. Engineering Business Management, 4(30), 1-8.

Anonymous. (2012). Global warming potentials. Retrieved February 20, 2012, from www.eeocw.org/get-involved/global-warming-potential

Birol, F., \& Guerer, N. (1993), Modelling the transport sector fuel demand for developing economies. Energy Policy, Butterworth-Heinemann limited, United Kingdom, 1163-1172.

Global Environment Facility (GEF). (2010). Manual for calculating greenhouse gas benefits for global environment facility transportation projects (pp. 1-31). Washington D.C.: GEF/C.39/Inf.16.

Igwenagu, C. M. (2011). Principal component analysis of global warming with respect to $\mathrm{CO}_{2}$ emission in Nigeria: an exploratory study. Asian Journal of Mathematics and Statistics, 4(2), 71-80. http://dx.doi.org/10.3923/ajms.2011.71.80

Jones \& Stokes. (2007). Addressing Global Warming (Climate Change) in CEQA and NEPA Documents in the Post AB 32 Regulatory Environments. Retrieved July 27, 2012, from www.climatechangefocusgroup.com

Kane, S., \& Shogren, J. (2000). Linking adaptation and mitigation in climate change policy. Climate change, 45, 75-102. http://dx.doi.org/10.1023/A:1005688900676

Lindzen, S. R. (1992). Global warming: origin and nature. Retrieved March 7, 2013, from www.cato.org/pubs/regulation/reg15n2g.html 
Michaelis, L. (1997). Transport sector-strategies markets, technology and innovation. Energy policy, 25(14-15), 1163-1171. http://dx.doi.org/10.1016/S0301-4215(97)00108-0

Moen, E. (2012). Vehicle emissions and health impacts in Abuja, Nigeria.

Munasinghe, M., \& Swart, R. (2005). Primer on climate change and sustainable development: facts, policy analysis applications. Cambridge: Cambridge University Press. http://dx.doi.org/10.1017/CBO9780511622984

Muneer, T., Celik, A. N., \& Canskan, N. (2011), Sustainable transport for a medium sized town in Turkey- a case study. Sustainable Cities and Society, 1, 23-37. http://dx.doi.org/10.1016/j.scs.2010.08.004

Musbau, R. (2012). Traffic gridlock, road safety and traffic radio. Business day Newspaper, July 12, 14.

Ndoke, P. N., Akpan, U. G., \& Kato, M. E. (2012), Contributions of Vehicular Traffic to Carbon Dioxide Emissions in Kaduna and Abuja, Northern Nigeria. Leonardo Electronic Journal of Practices and Technologies. Retrieved May 23, 2012, from http://webmail.academicdirect.org/cgi-bin/openwebmail

Nneji, F. (2006). The benefits of good transport system in Nigeria. Business day Newspaper.

Perez, P., Ortega, M., Martin, B., Otero, I., \& Monzon, A. (2013). Transport planning and global warming. Retrieved March 15, 2013, from www.cdn.intechweb.org/pdfs/12174.pdf

Robinson, R. (1997). Transportation demand Management in Canada: an overview. Energy Policy, 25, 1189-1191. http://dx.doi.org/10.1016/S0301-4215(97)00120-1

The Nigerian Engineer. (2012). 2011 in reminiscence: The Nigerian Society of Engineers' 2011 conference and annual general meeting. Magazine of the Nigerian Society of Engineers, 4-6.

Utang, P. B., \& Peterside, K. S. (2011). Spatio-temporal variations in urban vehicular emission in Port Harcourt city, Nigeria. Retrieved March 7, 2012, from http://dx.doi.org/10.4314/ejesm.v4i2.5

Wilbank, T. J., Kane, S. M., Leiby, P. N., Perlack, R. D., Settle, C., Shogren, J. F., \& Smith, J. B. (2003). Integrating mitigation and adaptation - possible responses to global climate change. Environment, 45, 28-38. http://dx.doi.org/10.1080/00139150309604547 